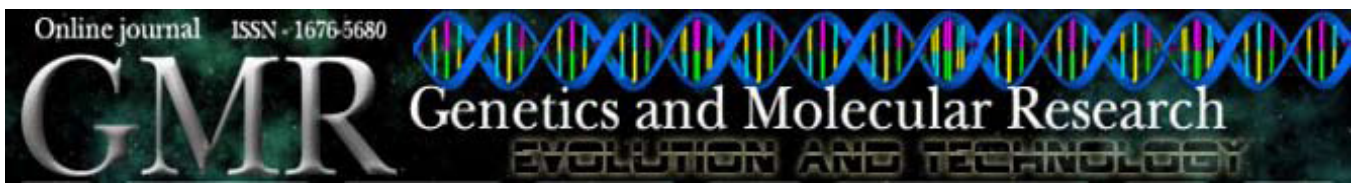

\title{
Association of single nucleotide polymorphisms with carcass traits in Nellore cattle
}

\author{
J.B.S. Ferraz ${ }^{1}$, L.F.B. Pinto ${ }^{2}$, F.V. Meirelles ${ }^{1}$, J.P. Eler ${ }^{1}$, F.M. de Rezende ${ }^{1}$, \\ E.C.M. Oliveira ${ }^{1}$, H.B. Almeida ${ }^{3}$, B. Woodward ${ }^{4}$ and D. Nkrumah ${ }^{4}$ \\ ${ }^{1}$ Departamento de Ciências Básicas, \\ Faculdade de Zootecnia e Engenharia de Alimentos, \\ Universidade de São Paulo, Pirassununga, SP, Brasil \\ ${ }^{2}$ Departamento de Produção Animal, Escola de Medicina Veterinária, \\ Universidade Federal da Bahia, Salvador, BA, Brasil \\ ${ }^{3}$ Merial Saúde Animal Ltda., Campinas, SP, Brasil \\ ${ }^{4}$ Merial Limited, Duluth, GA, USA \\ Corresponding author: J.B.S. Ferraz \\ E-mail: jbferraz@usp.br
}

Genet. Mol. Res. 8 (4): 1360-1366 (2009)

Received July 7, 2009

Accepted August 27, 2009

Published November 17, 2009

\begin{abstract}
The association between two single nucleotide polymorphisms (SNPs), T945M and UCP1SNP1, with hot carcass weight (HCW, kg, $\mathrm{N}=618$ ), longissimus dorsi muscle area (REA, $\mathrm{cm}^{2}, \mathrm{~N}=633$ ), and backfat thickness ( $\left.\mathrm{BF}, \mathrm{mm}, \mathrm{N}=625\right)$, measured in Nellore cattle in Brazil, was evaluated. Likelihood ratio tests were used to evaluate reduced (fixed effects of general mean, contemporary group, yearling weight, age at slaughter, and random effect of infinitesimal genetic value) and full model (reduced model effects plus quantitative trait locus effects). Additive and dominance effects were tested for each SNP. Genotypic and gene frequencies were also obtained for the SNPs and a descriptive phenotype analysis was made. Mean values for $\mathrm{HCW}, \mathrm{REA}$ and BF were equal to $288.13 \pm 0.55 \mathrm{~kg}, 73.14 \pm 0.27 \mathrm{~cm}^{2}$, and $4.28 \pm 0.07 \mathrm{~mm}$, respectively; the coefficients of variation were 4.74, 9.24, and 42.43\%, respectively. Gene frequencies for $T 945 M$ and UCP1SNP1 were $\mathrm{f}(\mathrm{C})=0.89, \mathrm{f}(\mathrm{T})=0.11, \mathrm{f}(\mathrm{C})=0.81$, and $\mathrm{f}(\mathrm{G})=0.19$. The SNP T945M had a genotypic frequency of only three animals for
\end{abstract}


TT genotype. Additive effects were observed for T945M on REA and $\mathrm{BF}$, while UCP1SNP1 affected HCW and BF. Based on the significant additive effects of the SNPs and the gene frequencies that we found, we can expect genetic gains with marker assisted selection.

Key words: Bos indicus; Leptin; Linkage disequilibrium; Markers; UCP1

\section{INTRODUCTION}

Longissimus muscle area (ribye area, REA), backfat thickness (BF) and hot carcass weight $(\mathrm{HCW})$ are correlated with carcass quality and indicate edible meat yield in carcasses. However, carcass traits are difficult or expensive to evaluate in breeding programs, because it is necessary to slaughter animals or measure animals with ultrasound equipment. Molecular marker information can be a useful tool for estimating breeding values and selecting animals for carcass traits. Additionally, selection processes could start earlier, even before phenotypic expression.

The importance of leptin in metabolism has resulted in many studies aimed at searching for polymorphisms in the leptin or leptin receptor genes. Associations with obesity in mice and humans were observed by Zhang et al. (1994) and Montague et al. (1997), respectively. Thus, single nucleotide polymorphisms (SNPs) that identify mutations in the leptin or leptin receptor genes have been tested to determine associations with economically relevant traits in cattle. Liefers et al. (2004) found associations between SNPs in the leptin gene and circulating leptin levels in cows during the final phase of gestation. Lagonigro et al. (2003) found associations of SNPs in the leptin gene with feed intake. Nkrumah et al. (2005) tested an association of leptin SNPs with carcass traits obtained by ultrasound in crossbred Bos Taurus cattle, but there are no reports of associations with carcass traits, measured after slaughter, in Bos indicus, as in the present study.

Uncoupling proteins (UCP) are located in the mitochondrial membrane. They work as an alternative channel for protons located in the intermembrane space, as they return to the mitochondrial matrix (Bouillaud et al., 2001). When UCP are stimulated, the protons cannot enter into the mitochondrial matrix through that alternative channel. It causes a reduction in ATP production and an increase in heat yield due to additional substrate oxidation, and of course, that results in implications on body weight regulation. In cattle, the UCP1 (uncoupling protein 1) gene is located on chromosome 17 (Sonstegard and Kappes, 1999) and SNPs in this gene were not previously reported as being associated with carcass traits.

Thus, the present study was designed to test the association of SNPs in the leptin and UCP genes with REA, BF, and HCW in Nellore cattle.

\section{MATERIAL AND METHODS}

\section{Population}

Phenotypic and genotypic information of 638 intact Nellore bulls were used. All animals were the progeny of bulls selected for production and reproduction traits and controlled 
under a selection program designed to produce commercial bulls. Animals were raised under pasture conditions until 18 months of age and then fed in feedlots until harvest at 22 to 26 months of age in 2006. Cattle were harvested on six different dates, always early in the morning and after approximately $16 \mathrm{~h}$ of fasting.

\section{Phenotypic traits}

After slaughter, carcasses were sawed longitudinally to the middle and weighed to obtain $\mathrm{HCW}$. Next, they were chilled for $24 \mathrm{~h}$ at $2^{\circ} \pm 1^{\circ} \mathrm{C}$. Afterward, samples of the longissimus dorsi muscle were taken between the 12th and 13th ribs, always on the same carcass side. At that cut, the REA was measured, with a transparent grid. BF was also measured between the 12th and 13th ribs at three-quarters of the distance from the lateral end of the longissimus dorsi muscle.

\section{Genotyping and molecular markers}

SNP T945M is located on chromosome 3 in the leptin receptor gene. It is a cytosine to thymine base substitution at position 115 , which results in a substitution of the amino acid threonine by methionine at residue 945 of leptin. More details can be found in Liefers et al. (2004). All three genotypes (CC, CT, and TT) were observed for this mutation in the sample of 638 animals.

UCP1SNP1 SNP is located on bovine chromosome 17 and it is a silent mutation in intron 1 of the UCP gene, as described by Sonstegard and Kappes (1999). All three genotypes (CC, CG, and GG) were also observed for this mutation in the sample of 638 animals.

DNA samples were obtained from blood or hair follicles. Genotypes were determined by DNA mass spectrometry (Sequenom Plex $^{\mathrm{TM}}$ Mass Spec), which was carried out at IGENITY ${ }^{\circledR}$ (Duluth, GA, USA), a Merial Ltd. subdivision that owns the exploration licenses. Polymerase chain reactions used approximately $120 \mathrm{ng}$ DNA, diluted in $25 \mu \mathrm{L}$, containing $0.2 \mu \mathrm{M}$ of each dNTP, $0.5 \mathrm{U}$ Taq DNA polymerase and $0.2 \mu \mathrm{M}$ of each oligonucleotide primer, and consisted of 32 cycles of $1 \mathrm{~min}$ at $94^{\circ} \mathrm{C}, 30 \mathrm{~s}$ at $58^{\circ} \mathrm{C}$ and $1 \mathrm{~min}$ at $72^{\circ} \mathrm{C}$.

\section{Statistical analysis}

Allele and genotype frequencies for $T 945 M$ and $U C P 1$ were obtained using SAS PROC FREQ (SAS, 2004). Associations between SNPs and traits were studied with the QXPAK software (Pérez-Enciso and Misztal, 2004). A likelihood ratio test (LRT) was conducted using a reduced model:

$$
Y_{i j}=\mu+C G_{i}+\alpha_{i j}(O)+\beta_{i j}(W)+\lambda_{i j}(I)+e_{i j}
$$

(Equation 1)

where $Y_{i j}$ is the phenotypic value of the $j^{\text {th }}$ animal in the $\mathrm{i}^{\text {th }}$ contemporary group, $\mu$ is the general mean of the trait, $\mathrm{CG}_{\mathrm{i}}$ is the fixed effect of $\mathrm{i}^{\text {th }}$ contemporary group, $\alpha_{\mathrm{ij}}$ is the coefficient for the covariate age at slaughter (only adjusted for hot carcass weight), $\beta_{\mathrm{ij}}$ is the coefficient for the yearling weight covariate, $\lambda_{\mathrm{ij}}$ is the coefficient associated with random effect of infinitesimal genetic value, and $e_{i j}$ is the random effect of the residual value.

Additive effect was tested using the full model: 


$$
Y_{i j}=\mu+C G_{i}+\alpha_{i j}(O)+\beta_{i j}(W)+\lambda_{i j}(I)+\delta_{i j}(A)+e_{i j} \quad \text { (Equation 2) }
$$

where the new term is the coefficient $\delta_{\mathrm{ij}}$ associated with the additive effect of the $\mathrm{j}^{\text {th }}$ animal in the $\mathrm{i}^{\text {th }}$ contemporary group.

Dominance effect was tested using the full model:

$$
Y_{i j}=\mu+C G_{i}+\alpha_{i j}(O)+\beta_{i j}(W)+\lambda_{i j}(I)+\gamma_{i j}(D)+e_{i j} \quad \text { (Equation 3) }
$$

where the new term is the coefficient $\gamma_{\mathrm{ij}}$ associated with the dominance effect of the $\mathrm{j}^{\text {th }}$ animal in the $i^{\text {th }}$ contemporary group. An LRT without infinitesimal genetic value was also performed to compare results.

\section{RESULTS AND DISCUSSION}

\section{Descriptive analysis and allele and genotype frequencies}

Descriptive statistics for $\mathrm{BF}$ and $\mathrm{HCW}$, presented in Table 1, are within the limits for the Brazilian national market demand, which rewards carcasses with BF ranging from 3 to $6 \mathrm{~mm}$ and hot HCW ranging from 270 to $300 \mathrm{~kg}$, as can be observed on the website of one of the largest beef packers in the country (www.independencia.com.br/pccc). The mean value for REA, also reported in Table 1, is lower than that of Luchiari Filho's (2000) recommendation. According to this author, a good carcass should have at least $29 \mathrm{~cm}^{2} \mathrm{REA} / 100 \mathrm{~kg} \mathrm{HCW}$, but in the present study we observed approximately $25.4 \mathrm{~cm}^{2}$ $\mathrm{REA} / 100 \mathrm{~kg} \mathrm{HCW}$. Bonilha et al. (2008) reported even lower values of $23.5 \mathrm{~cm}^{2} \mathrm{REA} / 100$ $\mathrm{kg}$ cold carcass weight in Nellore cattle. The coefficients of variation can be considered low for $\mathrm{HCW}$ and REA, but it is very high for BF, indicating great variability in the way this trait is measured in Nellore cattle.

Table 1. Descriptive analysis for hot carcass weight $(\mathrm{HCW})$, longissimus muscle area (REA) and backfat
thickness (BF).
\begin{tabular}{llrrrr}
\hline Trait & $\mathrm{N}^{1}$ & Mean \pm SE & Minimum & Maximum & CV \\
\hline HCW & 618 & $288.13 \pm 0.55$ & 255.50 & 329.00 & 4.74 \\
REA & 633 & $73.14 \pm 0.27$ & 56.00 & 93.00 & 9.24 \\
BF & 625 & $4.28 \pm 0.07$ & 1.00 & 9.00 & 42.43 \\
\hline
\end{tabular}

${ }^{1}$ Sample size. $\mathrm{CV}=$ coefficient of variance.

These markers were polymorphic in Nellore cattle (Table 2). All three possible genotypes for each SNP were found in this sample of 638 Nellore animals. However, the TT genotype for $T 945 \mathrm{M}$ was quite rare and only occurred in three animals. Very low genotype frequencies are always a problem in estimating additive effects. This is due to the contrast between averages of the homozygotes, and thus, the mean value of the rare genotype might have been under- or overestimated. The observed frequency of heterozygotes indicates that this maker could still be used for selection. 


\begin{tabular}{|c|c|c|c|c|c|}
\hline \multirow{2}{*}{$\begin{array}{l}\text { Marker } \\
U C P I S N P 1\end{array}$} & \multicolumn{2}{|c|}{ Gene frequencies } & \multicolumn{3}{|c|}{ Genotype frequencies } \\
\hline & $\mathrm{C}-0.81$ & $\mathrm{G}-0.19$ & $\mathrm{CC}=63.8$ & $\mathrm{CG}=33.4$ & $\mathrm{GG}=2.8$ \\
\hline$T 945 M$ & C -0.89 & $\mathrm{~T}-0.11$ & $\mathrm{CC}=79.2$ & $\mathrm{CT}=20.3$ & $\mathrm{TT}=0.50$ \\
\hline
\end{tabular}

\section{Association analysis}

The present study found a significant association between an SNP in the leptin receptor gene and REA in Nellore cattle. T945M is a mutation located on chromosome 3 at position 115 of exon 20 of the leptin receptor gene as stated previously. The additive effect of T945M was significantly $(\mathrm{P}<0.01)$ associated with REA (Tables 3 and 4$)$. The largest mean value was observed for CC genotype, a difference of $1.95 \mathrm{~cm}^{2}$ for the TT genotype when adjusted for infinitesimal genetic value (Table 4) and $2.59 \mathrm{~cm}^{2}$ without adjusting for infinitesimal effect (Table 3). This same marker was significantly associated with $\mathrm{BF}(\mathrm{P}<0.05)$, and again, the $\mathrm{CC}$ genotype produced a larger average than the TT genotype, a difference of $0.40 \mathrm{~mm}$ in fat thickness (Table 3, without adjustment for infinitesimal value), or 0.34 (Table 4, with adjustment for infinitesimal value).

Table 3. Quantitative trait loci for backfat thickness (BF), longissimus muscle area (REA) and hot carcass weight $(\mathrm{HCW})$ in the model without infinitesimal genetic value adjusted.

\begin{tabular}{lccccc}
\hline Trait & Marker & Type of effect & $\begin{array}{c}\text { Effect SE } \\
\text { (mean } \pm \text { SE) }\end{array}$ & $\begin{array}{c}\text { LRT } \\
\text { Nominal } \\
\text { P value }\end{array}$ \\
\hline HCW & UCPISNPI & A & $-2.19 \pm 0.89$ & 5.95 & 0.01470 \\
& & D & $-0.42 \pm 0.15$ & 8.07 & 0.00450 \\
REA & T945M & A & $2.59 \pm 0.61$ & 17.54 & 0.00003 \\
& & D & $-2.69 \pm 0.65$ & 16.99 & 0.00004 \\
BF & T945M & A & $-0.40 \pm 0.17$ & 4.90 & 0.01520 \\
BF & DCPISNPI & A & $0.36 \pm 0.16$ & 4.72 & 0.03860 \\
& & D & $0.28 \pm 0.13$ & 8.05 & 0.02980 \\
\hline
\end{tabular}

$\mathrm{SE}=$ standard error; $\mathrm{LRT}=$ likelihood ratio test.

Table 4. Quantitative trait loci for fat thickness (BF), longissimus muscle area (REA) and hot carcass weight $(\mathrm{HCW})$ in the model that considers adjustment for infinitesimal genetic value.

\begin{tabular}{|c|c|c|c|c|c|}
\hline Trait & Marker & Type of effect & $\begin{array}{c}\text { Effect (SE) } \\
(\text { mean } \pm \text { SE) }\end{array}$ & LRT & $\begin{array}{l}\text { Nominal } \\
\text { P value }\end{array}$ \\
\hline \multirow[t]{2}{*}{$\mathrm{HCW}$} & UCPISNP1 & A & $-1.66 \pm 0.93$ & 3.23 & 0.0725 \\
\hline & & $\mathrm{D}$ & $-0.38 \pm 0.15$ & 6.48 & 0.0109 \\
\hline \multirow[t]{2}{*}{ REA } & T945M & $\mathrm{a}$ & $1.95 \pm 0.64$ & 9.08 & 0.0026 \\
\hline & & d & $-2.07 \pm 0.67$ & 9.31 & 0.0023 \\
\hline \multirow[t]{2}{*}{$\mathrm{BF}$} & T945M & $\mathrm{a}$ & $-0.34 \pm 0.17$ & 3.68 & 0.0549 \\
\hline & & d & $0.29 \pm 0.16$ & 2.55 & 0.1100 \\
\hline \multirow[t]{2}{*}{$\mathrm{BF}$} & UCPISNPI & $\mathrm{a}$ & $0.24 \pm 0.13$ & 3.47 & 0.0625 \\
\hline & & d & $-0.38 \pm 0.15$ & 6.46 & 0.0110 \\
\hline
\end{tabular}

$\mathrm{SE}=$ standard error; $\mathrm{LRT}=$ likelihood ratio test. 
T945M showed a similar LRT significance when models were adjusted with or without yearling weight covariate. Therefore, the model with covariate is more suitable because the additive effect is tested directly on the trait and not indirectly as a consequence of possible effect on body weight. The favorable $\mathrm{C}$ allele is present at a high frequency (0.89), thus genetic improvement using its information may be reduced. For $\mathrm{BF}$ the $\mathrm{C}$ allele is dominant to the $\mathrm{T}$ allele, but for REA there is an overdominance effect and animals with the TC genotype have larger REA than CC or TT genotypes.

The leptin hormone is synthesized by adipose tissue, and it has an important function in metabolism and body weight control. Thus, SNP markers in the leptin or receptor leptin genes have been studied to identify associations with economically important traits in cattle, as reported by Lagonigro et al. (2003), Liefers et al. (2004), and Nkrumah et al. (2005). Nkrumah et al. (2005) described associations of the markers UASMS2 and UASMS3, both in the leptin promoter region, with fat thickness obtained by ultrasound; however, they did not report associations with REA, a major difference between the present study and other studies is the sample size. Nkrumah et al. (2005) analyzing 150 composite beef cattle at the University of Alberta (131 steers and 19 bulls) found a difference of approximately $3 \mathrm{~cm}^{2}$ in REA between the $\mathrm{CC}$ and TT genotypes of the marker UASMS2, although that difference was not significant, maybe due to sample size and model of analysis.

Uncoupling proteins are located on the mitochondrial membrane, and they work as alternative channels for protons in the intermembrane space as they return to the mitochondrial matrix (Bouillaud et al., 2001). When these proteins are stimulated, the protons do not enter into the mitochondrial matrix through this alterative channel, resulting in reduced ATP production and an increase in heat yield due to greater need of substrate oxidation, which has implications on body weight control. The UCP gene is expressed exclusively in brown adipose tissue and in humans it is involved in body weight control according to Bouillaud et al. (2001), and the marker UCP1SNP1 is a mutation located on bovine chromosome 17 (Sonstegard and Kappes, 1999). Although UCP1 is a good candidate gene for body development studies, no reference of an association of SNPs in the UCP1 gene with carcass trait in beef cattle was found in the literature. In the current study, this marker was associated with $\mathrm{HCW}$, in which animals with the GG genotype were $2.19 \mathrm{~kg}$ heavier than those with the CC genotype (Table 3 ). This same marker was also associated with $\mathrm{BF}$, and again, animals with the GG genotype had $0.28 \mathrm{~mm}$ more BF than the CC genotype (Table 3). Very similar results were also found, when using models with and without the yearling weight covariate; therefore, it is an SNP that has a direct effect on $\mathrm{HCW}$ and $\mathrm{BF}$. The favorable G allele has a low frequency in the population (0.19), and thus, there is great potential to improve the trait through the UCP1SNP1 marker selection process. Further studies with this marker in Nellore cattle are important, because the $\mathrm{C}$ allele is dominant to the $\mathrm{G}$ in both traits ( $\mathrm{BF}$ and $\mathrm{HCW}$ ), and the high frequency in this population may be linked to other traits of this breed.

\section{IMPLICATIONS}

One important finding in the present study is the importance of modeling the random effect of infinitesimal genetic value. When infinitesimal effect is adjusted, there is no UCP1SNP1 additive effect on HCW and BF (Table 4); only the dominance effect remains significant. Similarly, T945M does not have any significant effect on BF when infinitesimal genetic value was 
included (Table 4). When the infinitesimal effect was used, more parameters are included in the model, but the sample size is the same. Consequently, there is a reduction in the power of the test and some significant effects are not identified. In the present study, the LRT for additive effects of T945M and UCP1SNP1 estimated with the infinitesimal model showed nominal P values very close to the threshold of $0.05 \%$, as seen in Table 4 . Therefore, an increase in the sample size may help detect those effects even using a complex infinitesimal model. Biologically, a model with an infinitesimal effect makes more sense than models without it, because it is possible to isolate other gene effects, besides the loci that are being studied, and also because all the effects are estimated jointly, which is closer to reality.

\section{ACKNOWLEDGMENTS}

The authors thank FAPESP for a postdoctoral scholarship (\#07/50736-2), FUNPEC/ RP for financial support for data collection, and Merial Saúde Animal/Igenity for genotyping animals.

\section{REFERENCES}

Bonilha SF, Tedeschi LO, Packer IU, Razook AG, et al. (2008). Evaluation of carcass characteristics of Bos indicus and tropically adapted Bos taurus breeds selected for postweaning weight. J. Anim. Sci. 86: 1770-1780.

Bouillaud F, Couplan E, Pecqueur C and Ricquier D (2001). Homologues of the uncoupling protein from brown adipose tissue (UCP1): UCP2, UCP3, BMCP1 and UCP4. Biochim. Biophys. Acta 1504: 107-119.

Lagonigro R, Wiener P, Pilla F, Woolliams JA, et al. (2003). A new mutation in the coding region of the bovine leptin gene associated with feed intake. Anim. Genet. 34: 371-374.

Liefers SC, Veerkamp RF, te Pas MF, Delavaud C, et al. (2004). A missense mutation in the bovine leptin receptor gene is associated with leptin concentrations during late pregnancy. Anim Genet. 35: 138-141.

Luchiari Filho A (2000). Pecuária da Carne Bovina. 1st edn. Luchiari Filho, São Paulo.

Montague CT, Farooqi IS, Whitehead JP, Soos MA, et al. (1997). Congenital leptin deficiency is associated with severe early-onset obesity in humans. Nature 387: 903-908.

Nkrumah JD, Li C, Yu J, Hansen C, et al. (2005). Polymorphisms in the bovine leptin promoter associated with serum leptin concentration, growth, feed intake, feeding behavior, and measures of carcass merit. J. Anim. Sci. 83: 20-28.

Pérez-Enciso M and Misztal I (2004). Qxpak: a versatile mixed model application for genetical genomics and QTL analyses. Bioinformatics 20: 2792-2798.

SAS (Statistical Analysis Systems) (2004). User’s Guide. Version 9.1. SAS Institute Inc., Cary.

Sonstegard TS and Kappes SM (1999). Mapping of the UCP1 locus to bovine chromosome 17. Anim. Genet. 30: 472.

Zhang Y, Proenca R, Maffei M, Barone M, et al. (1994). Positional cloning of the mouse obese gene and its human homologue. Nature 372: 425-432. 